\title{
БИЗНЕС-ИНКУБАТОРЫ КАК ЭЛЕМЕНТ ИННОВАЦИОННОЙ ЭКОСИСТЕМЫ: СОВРЕМЕННОЕ СОСТОЯНИЕ И ТЕНДЕНЦИИ (ЧАСТЬ 2) *
}

\author{
(C) 2019 Хотяшева Ольга Михайловна \\ кандидат экономических наук \\ доцент кафедры менеджмента, маркетинга и ВЭД имени И.Н. Герчиковой \\ научный руководитель магистратуры «Отраслевой маркетинг товаров и услуг» МГИМО \\ директор Бизнес-инкубатора МГИМО \\ директор Фонда развития инноваций и бизнес-инкубаторства» МГИМО \\ Московский государственный институт международных отношений (университет) \\ Министерства иностранных дел Российской Федерации (МГИМО) \\ 119454, г. Москва, проспект Вернадского, 76 \\ (c) 2019 Слесарев Максим Александрович \\ Преподаватель кафедры Менеджмента, маркетинга и ВЭД имени И.Н. Герчиковой \\ заместитель директора Бизнес-инкубатора \\ Московский государственный институт международных отношений (университет) \\ Министерства иностранных дел Российской Федерации (МГИМО) \\ 119454, г. Москва, проспект Вернадского, 76
}

По данным Второго комплексного исследования рынка бизнес-инкубаторства, в 2016 г. в России насчитывалось порядка 250 бизнес-инкубаторов [6, с.4], однако в настоящее время наблюдается тенденция к сокращению их количества (по данным Министерства экономического развития, в 2018 г. их было всего 143). Одной из главных причин этого процесса авторы считают смену вектора государственной политики в данной сфере, а также общее сокращение расходов на действующую систему поддержки МСП, обусловленное, в частности, невыполнением многими существующими бизнес-инкубаторами спускаемых сверху показателей эффективности (количество принятых резидентов, объем проведенных тренингов, процент загрузки отведенных под аренду площадей и др.). Происходит же это в большинстве случаев не из-за низкого качества управления данными структурами, а в силу отсутствия ряда критически важных элементов ИЭС в регионах базирования соответствующих бизнес-инкубаторов и объективной невозможностью выполнения «плановых» показателей (например, низкая предпринимательская активность либо отсутствие доступа к венчурным инвестициям). Именно нехватку финансирования и сложность в привлечении ангельских и предпосевных инвестиций отмечают в качестве основной причины провала малых инновационных компаний 53\% российских бизнес-инкубаторов. Наивно полагать, что бизнес-инкубатор способен заменить собой инновационную экосистему и что его наличие в регионе автоматически приведет к бурному развитию предпринимательства и инновационного бизнеса.

На рисунке 3 видно, что большинство российских бизнес-инкубаторов (почти 60\%) относятся к инкубаторам смешанного типа (без ярко выраженной специализации), при этом наиболее редко встречаются структуры, специализирующиеся на компаниях сферы услуг (3,6\%). Тенденция к сокращению числа чисто сервисных бизнес-инкубаторов наблюдается на протяжении последних 5-6 лет: по сравнению с 2010 г., их доля снизилась на 2,4 процентных пункта (в среднем по миру этот показатель составляет всего 1\%). Доли производственных и технологических бизнес-инкубаторов также снижаются, однако не так заметно. В целом можно констатировать, что увязка на какой-либо конкретной специализации в России себя не оправдывает, поскольку может усугубить ситуацию с нехваткой клиентов. В общемировой практике доля смешанных инкубаторов не сильно ниже (54\%), однако количество технологических в разы больше $-39 \%$. Следует добавить, что в графе «Другое» $(14,3 \%)$ респонденты указывали в основном инновационную и социальную направленность своих резидентов.

Со спецификой деятельности бизнес-инкубаторов и стоящих перед ними задач связан тот факт, что лишь $7 \%$ инкубаторов в мире являют-

\footnotetext{
* Продолжение статьи авторов, опубликованной в 12 номере журнала «Экономические науки» за 2018 год
} 


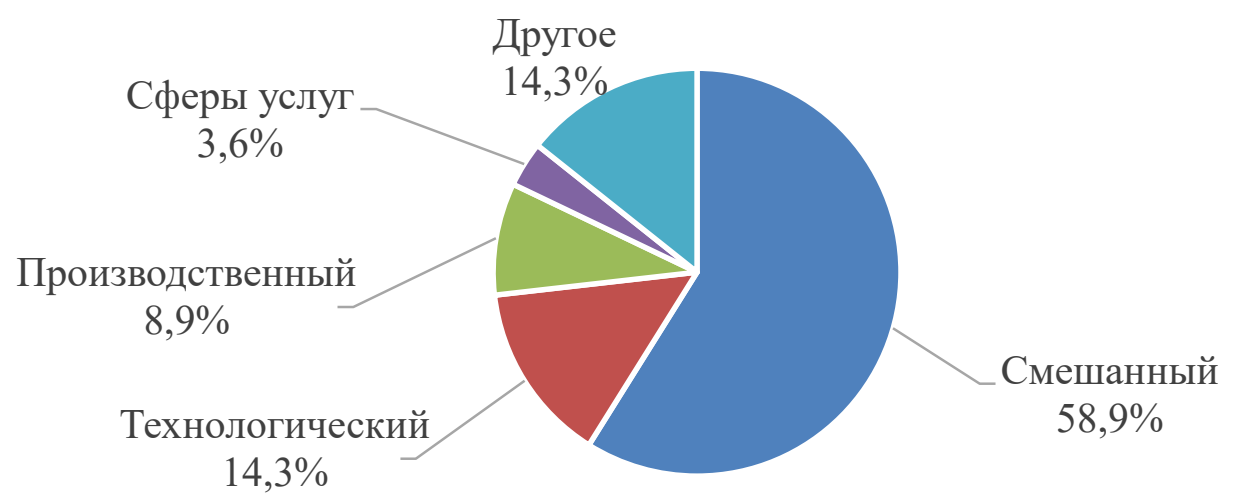

Puc. 3. Специализация бизнес-инкубаторов с точки зрения отраслевой принадлежности резидентов по состоянию на конец 2016 г.

Источник: Второе всероссийское исследование рынка бизнес-инкубаторства. Фонд развития инноваций и бизнес-инкубаторства, 2017. C. 6. http://www.ifbi.ru/research

ся прибыльными. В числе наиболее известных инкубаторов, получающих чистую прибыль от своей деятельности, можно назвать, например, Y Combinator и Plug and Play. В России число прибыльных инкубаторов существенно меньше, поскольку большинство из них являются бюджетными учреждениями или структурными подразделениями последних: почти половина всех инкубаторов находятся в собственности региональной администрации, 28\% - администрации вузов и $21 \%$ - муниципальной администрации. О частных бизнес-инкубаторах в России известно очень мало, и нередко само наименование «бизнес-инкубатор» не отражает реального содержания их деятельности.

Интересно, что по результатам исследования 28,6\% отечественных инкубаторов все же заявили о получении прибыли от своей деятельности, однако важно понимать, что доход от предоставления платных услуг у бюджетных организаций составляет лишь некоторую часть денежных поступлений, очевидно не покрывающую все затраты. Чтобы считаться «прибыльным» в полном смысле этого слова, необходимо как минимум обеспечивать все свои расходы без учета финансирования из бюджета (не говоря уже о смещении главной цели деятельности с решения социально-экономических проблем на извлечение прибыли). Иными словами, словосочетание «прибыльный бизнес-инкубатор» по мнению авторов в большей степени применимо именно к успешным частным бизнес-инкубаторам и акселераторам. Более $17 \%$ российских бизнес-инкубаторов отмечают, что участвуют в уставном капитале своих резидентов $(15,1 \%$ участвуют в некоторых и лишь $1,9 \%$ - во всех без исключения), что ниже аналогичного показателя за рубежом $-24 \%$.

На рисунке 4 отражена специфика социальной ориентации российских бизнес-инкубаторов. Примечательно, что больше половины инкубаторов в России нацелены на поддержку

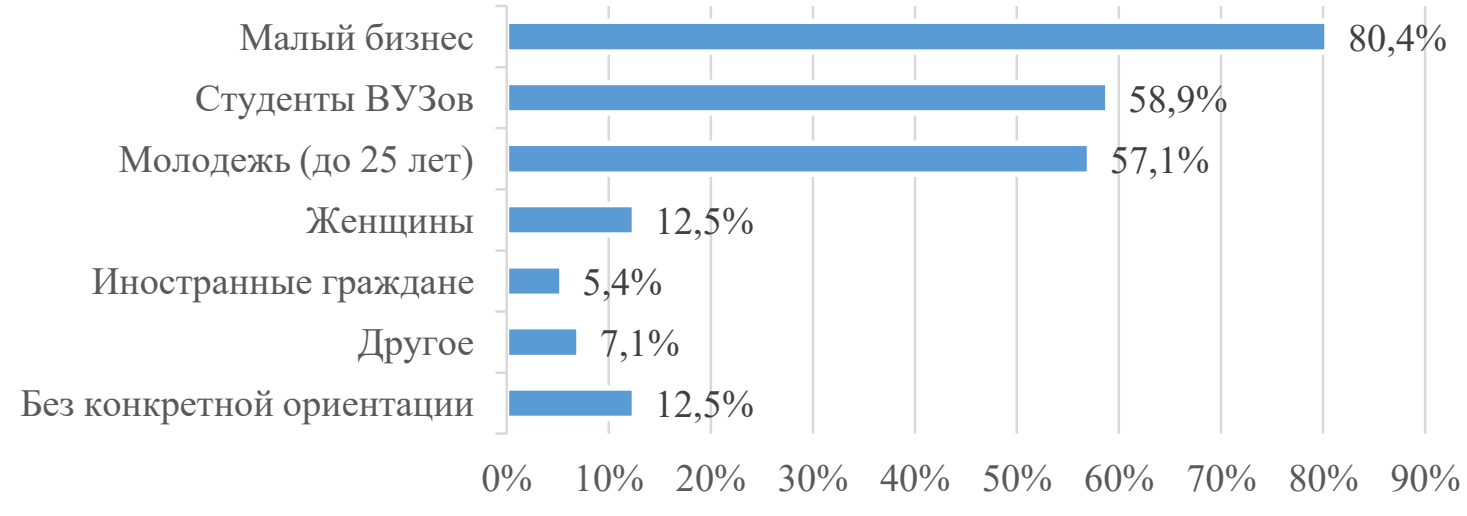

Puc. 4. Социальная ориентация российских бизнес-инкубаторов (\% от числа респондентов) Источник. Второе всероссийское исследование рынка бизнес-инкубаторства. Фонд развития инноваций и бизнес-инкубаторства, 2017. С. 7. http://www.ifbi.ru/research 
предпринимателей среди на студентов ВУЗов (58,9\%) и среди молодежи $(57,1 \%)$ в целом. В графе «Другое» отмечались такие варианты, как субъекты социального предпринимательства и научно-педагогический состав ВУЗов, однако их количество незначительно.

Интересно, что процент респондентов, отметивших ориентацию на ту или иную социальную группу, вырос по сравнению с 2011 г. практически по каждой категории. Особенно большие изменения наблюдаются по представителям малого бизнеса (увеличение с 44 до 80,4\%), студентам ВУЗов (с 33 до 58,9\%) и женщинам (с 2 до 12,5\%).

На рисунках 5 и 6 показаны соответственно структура обращающихся в бизнес-инкубаторы клиентов в зависимости от степени проработки проектов и возраста компаний. Главное изменение по сравнению с результатами исследования 2011 г. состоит в увеличении доли заявок, поступающих в инкубаторы от более опытных предпринимателей. Так, доля клиентов без собственной фирмы упала с 44 до 33,6\%, а доля клиентов с фирмами от 1 до 5 лет суммарно возросла с примерно 20 до 29,4\%. Как ни странно, структура с точки зрения степени проработки проектов осталась практически неизменной. Исходя из этого можно констатировать, что все больше уже действующих на рынке компаний обращаются в бизнес-инкубаторы с новыми идеями и проектами.

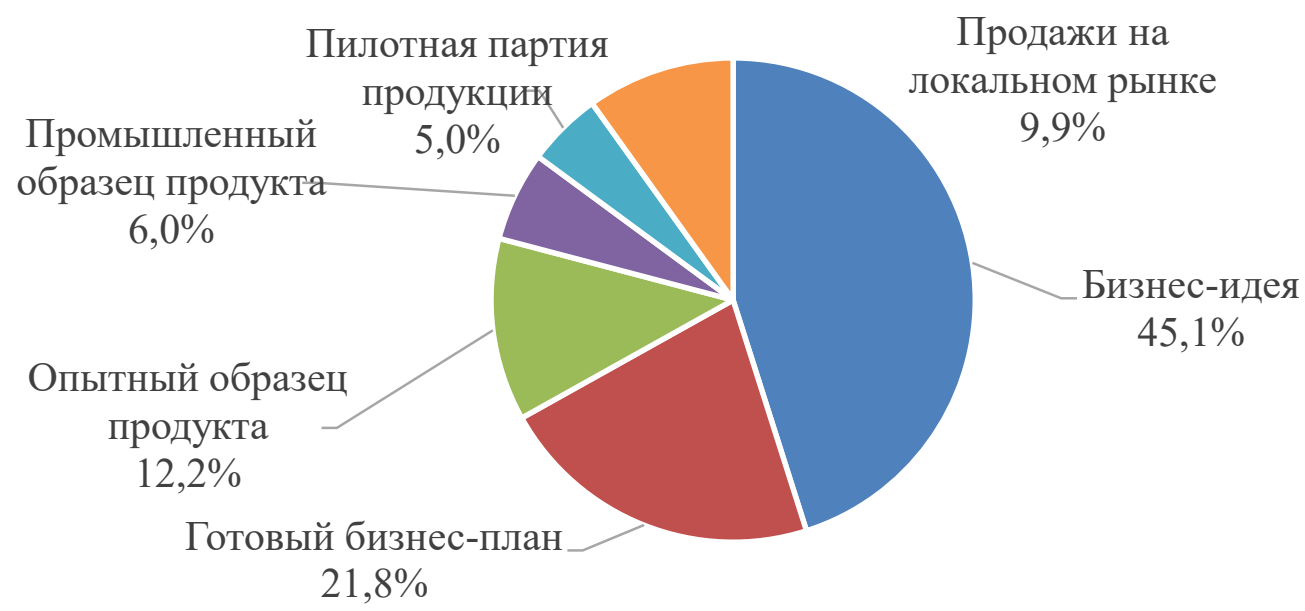

Puc. 5. Структура обращающихся в бизнес-инкубатор клиентов в зависимости от степени проработки проектов (в \% от общего числа)

Источник. Второе всероссийское исследование рынка бизнес-инкубаторства. Фонд развития инноваций и бизнес-инкубаторства, 2017. С. 7. http://www.ifbi.ru/research

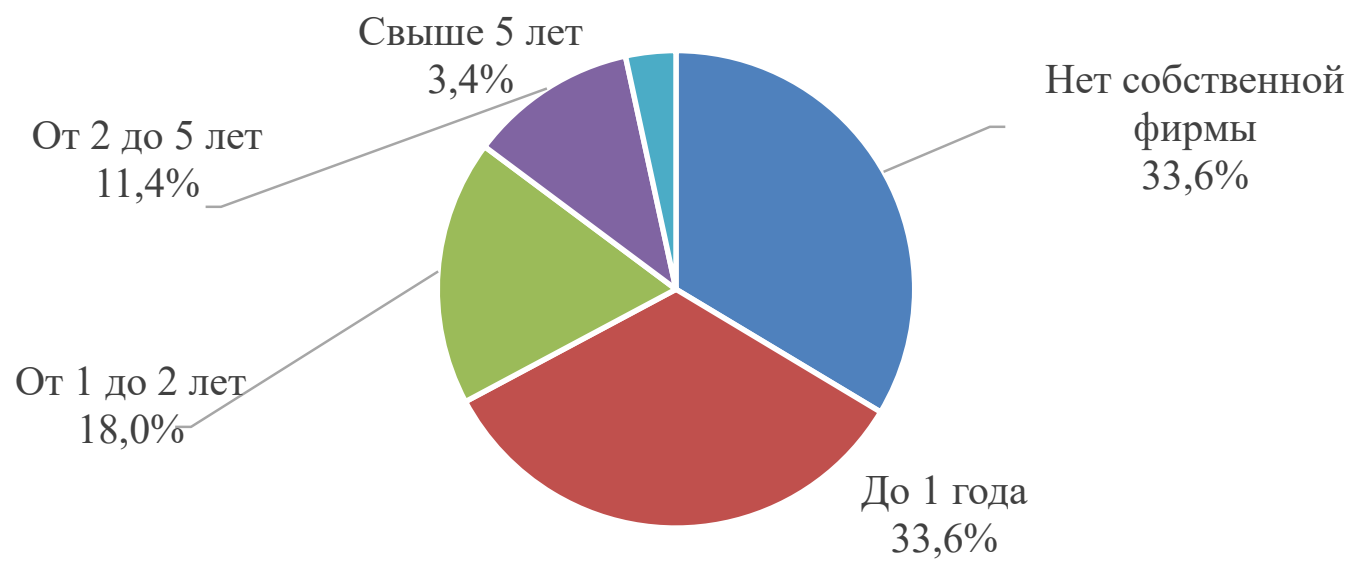

Puc. 6. Возрастная структура компаний, обращающихся в бизнес-инкубатор (в \% от общего числа) Источник. Второе всероссийское исследование рынка бизнес-инкубаторства. Фонд развития инноваций и бизнес-инкубаторства, 2017. С. 7. http://www.ifbi.ru/research 
Наиболее причиной выпуска компаний из российских бизнес-инкубаторов является достижение первыми максимальных сроков нахождения в программе. Учитывая, что средний период оказания услуг резидентам в России в полтора раза меньше, чем во всем мире -24 месяца,- указанная причина выпуска клиентов представляется весьма спорной. В то же время критерий «Потребности компании в рабочем пространстве превышают максимально допустимые по программе», который свидетельствует об относительно успешном развитии стартапов, был указан в качестве неиспользуемого каждым пятым инкубатором.

Рабочее пространство предоставляется 95\% российских бизнес-инкубаторов. Средняя площадь инкубатора составляет 2572 кв.м, из которых 59\% отведены под резидентов, 7,7\% - под якорных арендаторов, 18,9\% - под помещения общего пользования и 13,1\% площади заняты административными помещениями. Загрузка площадей, отведенных под сдачу в аренду резидентам, в 2017 г. составила 73\% (более четверти инкубаторов в России смогли достичь уровня $90 \%)$, что существенно выше аналогичного показателя 2011 г. (66,1\%), однако все еще ниже среднемирового уровня (80\%).

Говоря о финансовой стороне деятельности бизнес-инкубаторов, нельзя не отметить несколько особенностей. Во-первых, среднегодовой бюджет российских бизнес-инкубаторов существенно ниже среднемирового показателя -5 млн. руб. При этом почти $40 \%$ инкубаторов имеют годовой доход менее 1 млн. руб.
Во-вторых, главной статьей доходов является целевое бюджетное финансирование (40,1\% в структуре доходов), в то время как в среднем по миру наибольшую долю составляют рентные платежи от клиентов (59\%). Тревожным сигналом здесь является тот факт, что по сравнению с 2011 г. доля целевого бюджетного финансирования в доходе бизнес-инкубаторов не только не сократилась, а даже несколько увеличилась (на пару процентных пунктов). Доход от сдаваемых в аренду платежей является второй по важности статьей - на него приходится $28 \%$ бюджета (рисунок 8). Основным источником финансирования являются местные органы власти (30\% бизнес-инкубаторов) и ВУЗы (27\%). Менее $7 \%$ инкубаторов получают финансирование от коммерческих и некоммерческих организаций, частных спонсоров и инвесторов, а 9\% функционируют без какой-либо внешней финансовой поддержки.

B-третьих, в структуре издержек наблюдается сильный «перегиб» в сторону заработной платы - 52,9\% против среднемировых 36\%, причем эта доля продолжает расти. Главная статья затрат бизнес-инкубаторов в мире - инфраструктурные расходы (38\%), а в нашей стране на эти цели расходуется лишь 23,3\% средств (см. диаграмму 7), что отчасти может быть связано с относительной новизной инфраструктуры и недостаточной загрузкой рабочего пространства.

Достаточно заметным изменением в структуре расходов российских бизнес-инкубаторов с 2011 г. является перераспределение затрат на реализация программы бизнес-инкубаторства

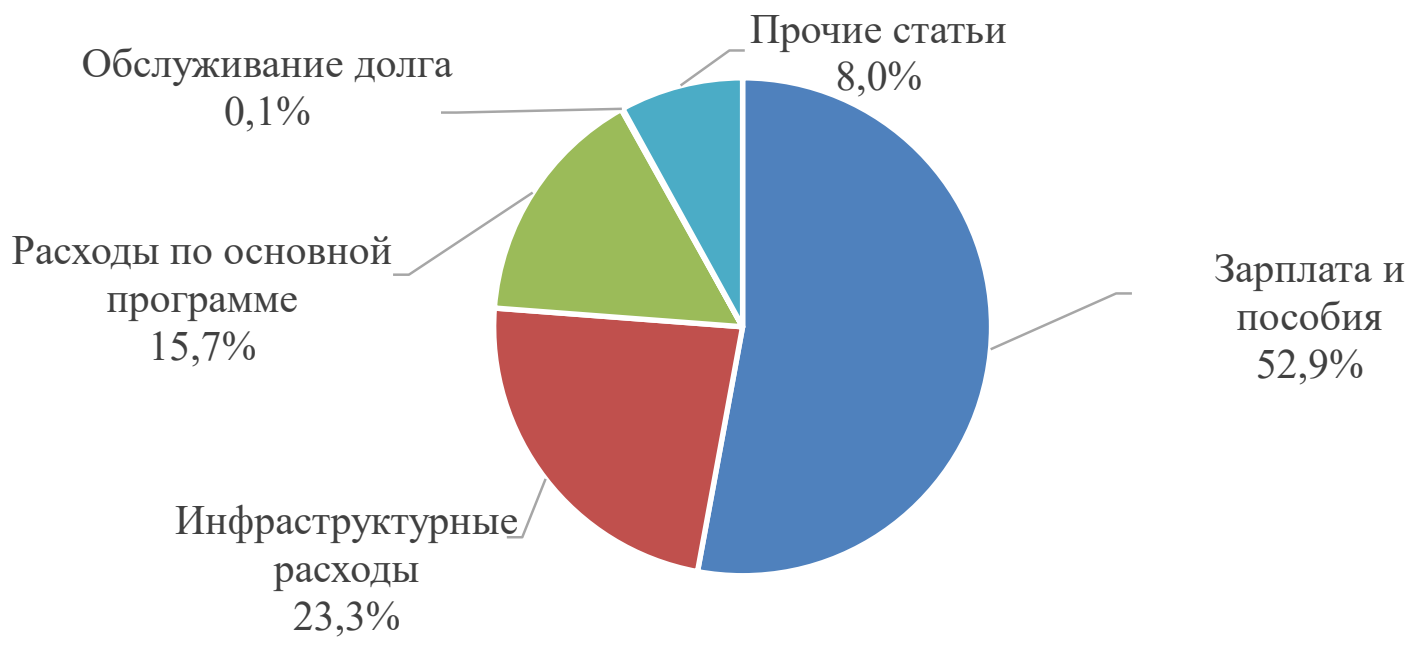

Puc. 7. Усредненная структура расходов российских бизнес-инкубаторов, 2016 г. Источник. Второе всероссийское исследование рынка бизнес-инкубаторства. Фонд развития инноваций и бизнес-инкубаторства, 2017. С. 12. http://www.ifbi.ru/research 


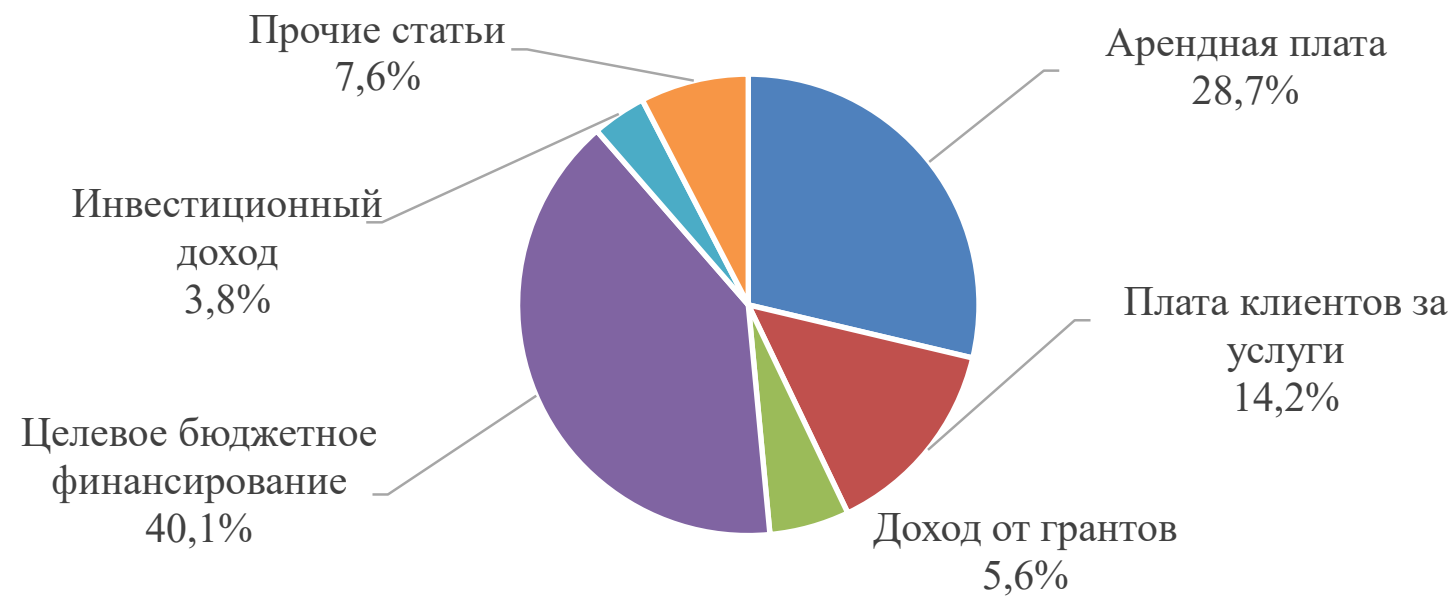

Puc. 8. Усредненная структура доходов российских бизнес-инкубаторов, 2016 г. Источник. Второе всероссийское исследование рынка бизнес-инкубаторства. Фонд развития инноваций и бизнес-инкубаторства, 2017. С. 12. http://www.ifbi.ru/research

Таблица 3. Усредненный портрет российского и мирового бизнес-инкубатора, 2016 г.

\begin{tabular}{|l|l|l|}
\hline \multicolumn{1}{|c|}{ Характеристика } & \multicolumn{1}{|c|}{ Россия } & \multicolumn{1}{c|}{ Мир } \\
\hline Общая площадь, кв.м. & 2572 & 3700 \\
\hline Штат, чел. & 15 & 12 \\
\hline $\begin{array}{l}\text { Среднегодовое количество } \\
\text { резидентов }\end{array}$ & 18 & 35 \\
\hline $\begin{array}{l}\text { Среднегодовое количество якор- } \\
\text { ных арендаторов }\end{array}$ & 4 & 3 \\
\hline $\begin{array}{l}\text { Средний период оказания услуг } \\
\text { резидентам, мес. }\end{array}$ & 24 & 33 \\
\hline $\begin{array}{l}\text { Среднее число сотрудников одного } \\
\text { резидента }\end{array}$ & $73 \%$ & $4-5$ \\
\hline $\begin{array}{l}\text { Средняя загрузка площадей } \\
\text { резидентами }\end{array}$ & 5 млн. руб. & $80 \%$ \\
\hline Среднегодовой бюджет & $\begin{array}{l}\text { фелевое бюджетное } \\
\text { финансирование (40,1\%) }\end{array}$ & Рен-600 тыс. долл. \\
\hline Основной источник доходов & Зарплата (52,9\%) & Инфраструктурные расходы (38\%) \\
\hline Основная статья расходов
\end{tabular}

Источник, Составлено авторами на основе данных InBIA и Фонда развития инноваций и бизнес инкубаторства МГИМO

(снижение с 34 до 15,7\%) в пользу расширения фонда оплаты труда (повышение с 36 до 52,9\%). Такое радикальное изменение авторы связывают с тем, что все больший спектр услуг по основной программе бизнес-инкубаторы реализуют силами собственных сотрудников, минимально привлекая внешних специалистов и подрядчиков. Этот фактор сложно однозначно трактовать как положительный или отрицательный.

На основе проведенного анализа можно сопоставить усредненные портреты российского и мирового бизнес-инкубатора по ряду наиболее важных критериев (см. табл. 3).

\section{Заключение}

Бизнес-инкубаторы являются одним из наиболее важных инструментов инновационного развития экономики и поддержки предпринимательства, начальных стадиях функционирования: предпосевной (pre-seed), посевной (seed), и стадии запуска (start-up).

Первое комплексное исследование бизнес-инкубаторов было проведено в 2012 году. Несомненно, за 4x летний период, к 2016 году произошли определенные количественные и качественные изменения сектора, однако говорить о значительной положительной динамике 
не приходится. Рост российского бизнес-инкубаторства с 2004-2005 годов, достаточно быстро сменился стадией зрелости, на которой обострились основные проблемные зоны: низкая активность и заинтересованность предпринимателей в услугах БИ (во многом из-за появления альтернативных возможностей), сложность в получении стартового капитала на предпосевной стадии, недостаток профессиональных кадров, низкая предпринимательская культура.

Мировой же опыт показывает, что БИ, ак- селераторы и технопарки являются базовыми элементами инновационных экосистем, и развитие предпринимательства зависит от уровня распространения и эффективности БИ, не меньше, чем от государственной поддержки МСП и доступности венчурного финансирования.

Таким образом, становится очевидна стратегическая приоритетность государственной поддержки института бизнес-инкубаторства как важнейшего субъекта экосистемы Российской Федерации.

\section{Библиографический список}

1. Федеральный закон от 24 июля 2007 г. N209-Ф3 «О развитии малого и среднего предпринимательства в Российской Федерации» (с изменениями и дополнениями)

2. Федеральный закон от 26 июля 2017 г. № 207-Ф3 О внесении изменений в статьи 4 и 4_1 Федерального закона «О развитии малого и среднего предпринимательства в Российской Федерации»

3. Приказ Министерства экономического развития РФ от 25 марта 2015 г. N167 «Об утверждении условий конкурсного отбора субъектов Российской Федерации, бюджетам которых предоставляются субсидии из федерального бюджета на государственную поддержку малого и среднего предпринимательства, включая крестьянские (фермерские) хозяйства, и требований к организациям, образующим инфраструктуру поддержки субъектов малого и среднего предпринимательства»

4. Единый реестр малых и средних предприятий, Портал Федеральной налоговой службы, 2017 https://ofd. nalog.ru/

5. Современные проблемы менеджмента, маркетинга и предпринимательства: монография / Н.Ю. Конина, Р.Б. Ноздрева, В.А. Буренин и др.- Москва: МГИМО-Университет, 2018.

6. Второе всероссийское исследование рынка бизнес-инкубаторства. Фонд развития инноваций и бизнес-инкубаторства, 2017. http://www.ifbi.ru/research

7. Хотящева О.М. Инновационный менеджмент: учебник и практикум для академического бакалавриата / О.М. Хотяшева, М.А. Слесарев. 3-е изд., перераб. и доп. Москва. 2017.

8. Перезагрузка мер поддержки малого и среднего предпринимательства. Трек: предложения по перезагрузке бизнес-инкубаторов. Upgrade-лаборатория при Минэкономразвития РФ, 2018. http://www.upgradelab.ru/ page-item8.html

9. WORLD TRADE REPORT 2016, Levelling the trading field for SMEs, https://www.wto.org/english/res_e/booksp_e/ world trade report16_e.pdf

10. Meredith Erlewine, Measuring Your Business Incubator's Economic Impact: A Toolkit, InBIA Publications, 2017

11. Mustafa Toruna, Laura Peconicka, Vinicius Sobreiroa, Herbert Kimuraa, Josep Pique. Assessing business incubation: A review on benchmarking // International Journal of Innovation Studies Vol. 2, Issue 3, September 2018

12. International Business Innovation Association. http://inbia.org 